\title{
Robot Based Preventive Maintenance System for In-Service Inspection of Equipments
}

\author{
Vimal Upadhyay \\ Indian Institute of Information Technology, Allahabad, India \\ Email: vimalupadhyay2002@gmail.com \\ Prof. G.N.Pandey \\ Indian Institute of Information Technology, Allahabad, India \\ Email: pandey63@gmail.com
}

\begin{abstract}
The current tendency in the petrochemical plants and Aerospace industry is to save weight and life of the equipments in the processing units, in order to reduce costs and to ensure remaining life of components. The world of today is improving with respect to new technologies. As a result, new composites are added to material for gaining a new shape and structure of material. This has made it compulsory for new innovative in non destructive testing specially in ultrasonic inspection, from conventional ultrasonic based on pulse echo method to phased array methods. In parallel to this innovative in ultrasonic, mechanical manipulator have evolved for grinding and take a setup to unapproachable zones. Industrial robot with ultrasonic inspection developed in this paper, with the collaboration of Indian Oil Corporation, Faridabad, India. Which are bringing reliability, durability, accuracy, flexibility, good maintenance and reproducibility for different sizing components to in-service inspection? This paper focused on the evolution of in-service ultrasonic probe with mechanical manipulator in non destructive testing. This evolution system has led to the current scenario systems, where a perfect combination of innovative methods in ultrasonic techniques and robots is meet to our expected delivers.
\end{abstract}

Index Terms - Non Destructive Testing, GW (Guided Wave), Pulse-Echo, Robotics

\section{INTRODUCTION}

This paper describes the evolution of in-service ultrasonic testing system for petrochemical and aeronautical components. Technetium working in the field of NDT since from last 50 years and having a 7oo+ NDT certificates[1][2]. There has been natural evolution of new technologies with respect to time in the field of mechanical manipulator, electrical manipulator and methods of pulse generation and receiving to the test piece. Initially we use a single element piezoelectric transducer, than we increase number of elements, leading finally to the electronically configuring system focusing and orientation towards ultrasonic beam (phased array). The latest breakthrough inservice monitoring is the generation of ultrasonic waves by a LASER, which provides a major advantage in ultrasonic methodologies of transmission and pulse echo. This entire breakthrough came in focus due to continuous research and optimization in the field of components inspection, manufacturing, shape, size, geometry and material

\section{A. Presence of Composites in components}

One of the most important parameter that directly affects the ultrasonic inspection is the components of material to be inspected. The current trend in the material science is to reduce the metals as much as extent to possible, increasing the presence of composites, which can directly reduce the weight $(20-50 \%)$, which has a good impact on lifting, fixtures and pumping motors or in others words we can say fuel savings[3]. It also improves other properties like resistance, fatigue, corrosion, material deterioration, as well as increase life of component and also reduces assembly cost. However some disadvantages also occur like (1) repair methods differ from those used earlier (2) increasing recurrent and non-recurrent costs. In aeronautical industry $50 \%$ of components consist of 5\% composites in place of original material from 1970. Consequently there is a dramatically change in weight, this progressive use of composite also lay important role in aircrafts programs, laminated parts of different thickness, sandwich components and honeycomb structures. When defining the in-service monitoring of these components, it is necessary to focus on the behavior of these components, when ultrasonic wave passes through it like attenuation, sending and receiving of signal pulse echo time.

\section{B. Geometry of composite Components}

Geometry is the aspect that influences the NDT inspection of components of working plants. All geometry and shape are lying in a series combination of $\mathrm{L}$, $\mathrm{T}, \mathrm{U}, \mathrm{H}$ and closed $\mathrm{H}$ type. These geometry shapes are define as the combinations of flat and curved surfaces.

The most typical geometries are omega and delta types. Figures 1 and 2 show conceptual and actual examples geometries used in components manufacturing. The essential geometric parameters for defining ultrasonic testing are: 1) thickness 2) radius 3) angle 4) cross section area. Ultrasonic in-service inspection is applied to those components, which fulfill the following condition:

- Thicknesses range: 1-50 mm

- Radii: 3 mm - without limit [9]

- Inner angles: $\left(80^{\circ}-180^{\circ}\right)$

- Outer angles: $\left(0^{\circ}-180^{\circ}\right)$ 

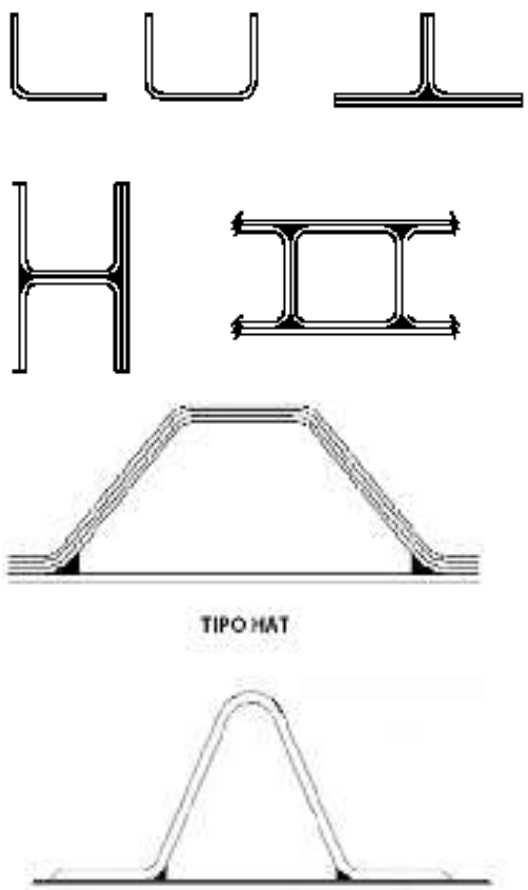

Fig. 1. Conceptual example of Geometry

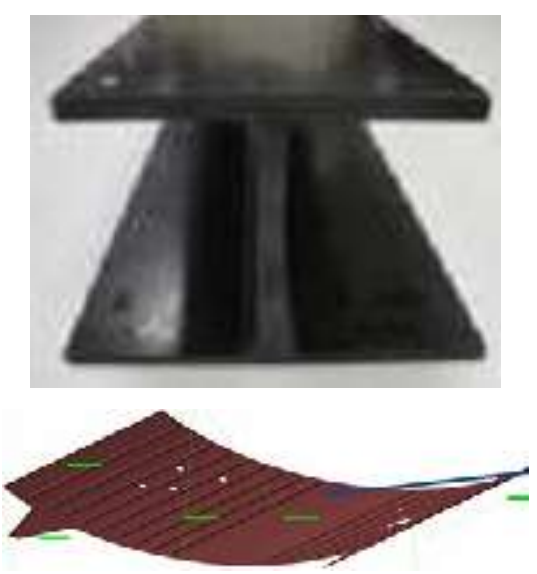

Fig. 2. Actual example of geometry

\section{Evolution of NDT Techniques}

The presence of different composite compounds, materials, shapes, size and geometries, as well as of different defects like leak, corrosion, erosion, bend and material deterioration to be detected with standard ultrasonic probe, standard means whenever non destructive testing inspection planned it is compulsory to follow certain set of rules called protocols for the definition and development. Initially evolution of non destructive testing based on the use of piezoelectric element (single element), single element means one transducer for sending and receiving a signal with delay. There are two possible configuration of piezoelectric transducer:

1) Through Transmission generally applicable for high attenuation materials. One of major disadvantage of this both side accessibility of component required to be inspected and it also not provide information of depth of defect.

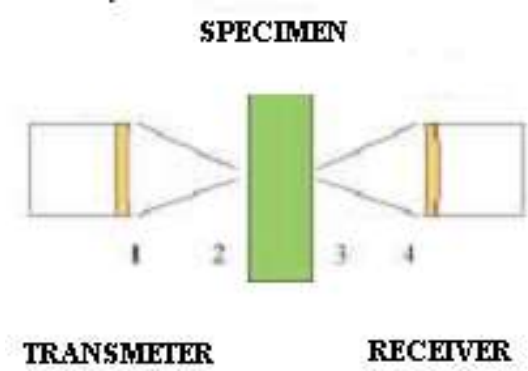

Fig. 3. Through Transmission Configuration

2) Pulse-echo method: component is accessible for single side for ultrasonic inspection. Advantages of pulse echo method: 1) it provide exact information to the depth of defect 2) applicable for high attenuation materials.
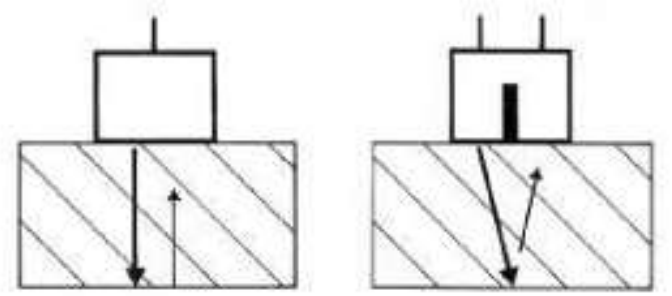

Fig. 4. Pulse Echo Configuration

The evolution in the field of non destructive testing has been the result of fair depth research of researchers. In the initial stage we use piezoelectric elements for transmission configuration than after some time pulse echo were developed, providing detailed information related to the depth of the defect. This was subsequently enhance day by day include multiple element piezoelectric system, and the next step is to generate ability of piezoelectric elements by which they communicate to each other by means of electronically. We reached to configurable ultrasonic beam that enhance the capabilities in enormously manner.

Manufacturing and maintenance costs of configurable beam greatly reduced in comparison to previous systems.

\section{Need of Mechanical Inspection Systems}

The manufacturing unit of aeronautical components, including monitoring has been automated in the recent years. The main objective of automation is: 1) to calculate the remaining life of components easily 2) reduce inspection time 3 ) inspection is easily possible at dangerous zones 4) inspection done in frequent manner 5) no risk of human causalities 6) to avoid shutdown due to components failure 7) $100 \%$ inspection of surface because crawler rotate all edge areas[4].

\section{E. Combination of NDT and Robots (electrical manipulator)}

The final result of this joint evolution of NDT techniques and ROBOTICS machines is combined together on a single platform, which allows us to bring accurate and reliable readings related to the components defect detected. The following figure shows the working of our model for customer satisfaction [5]. 


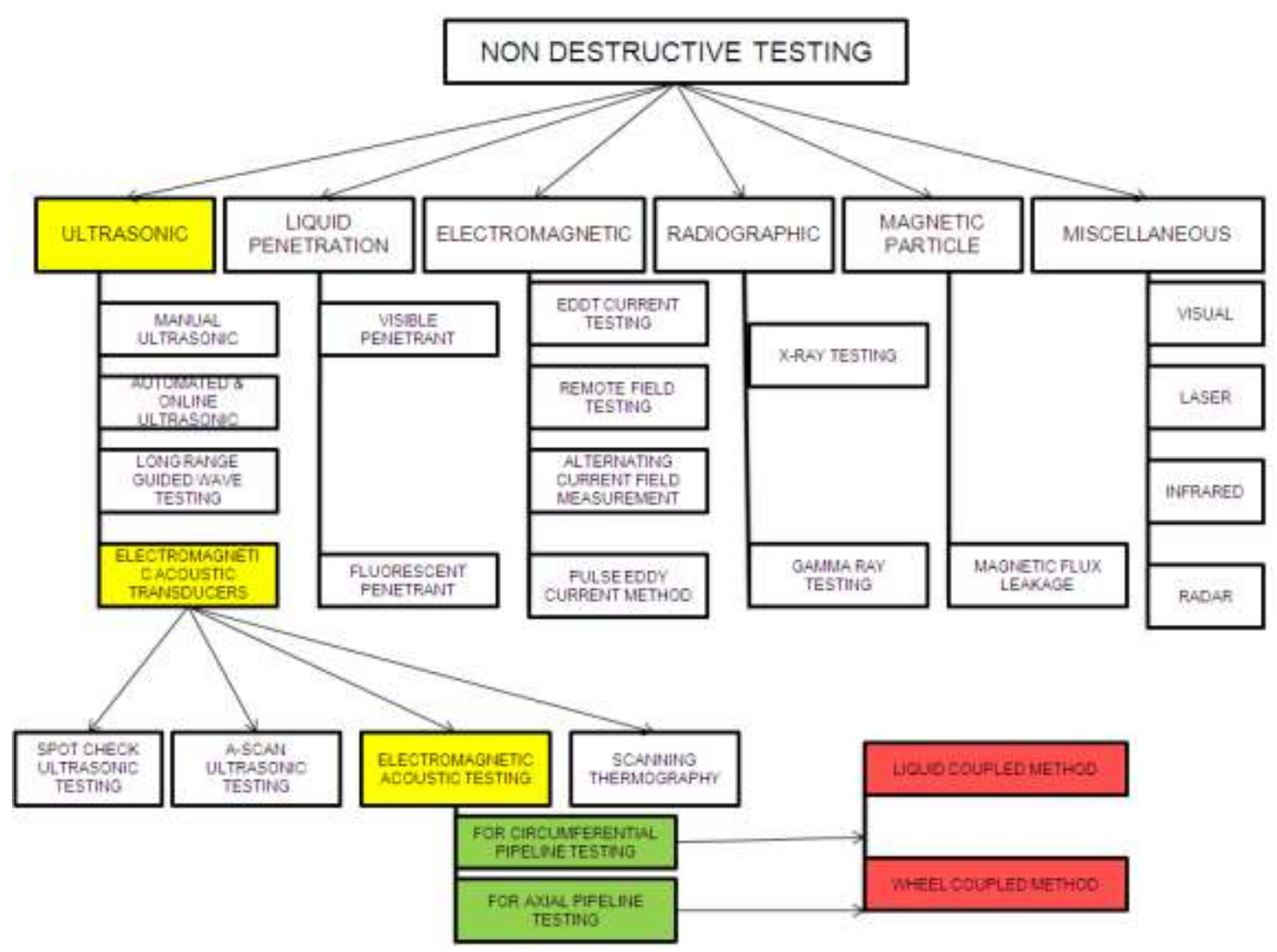

Fig. 5. Types of Non Destructive Testing

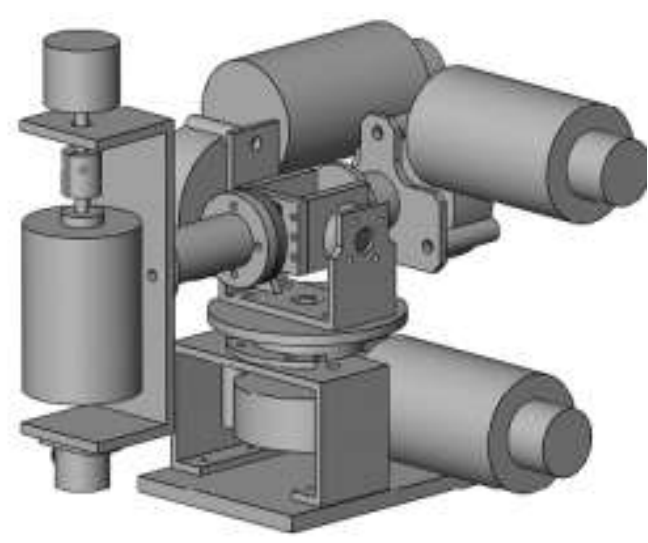

Fig. 6. Electronic Manipulator design in solid work

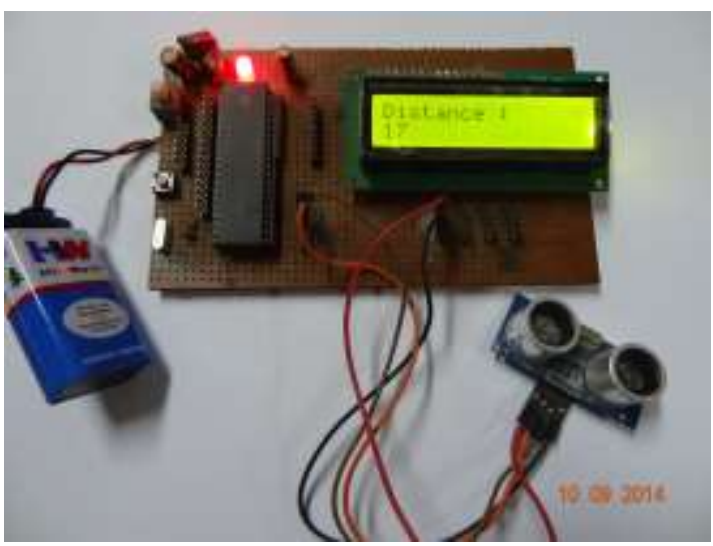

Fig. 7. Gap measurement modules

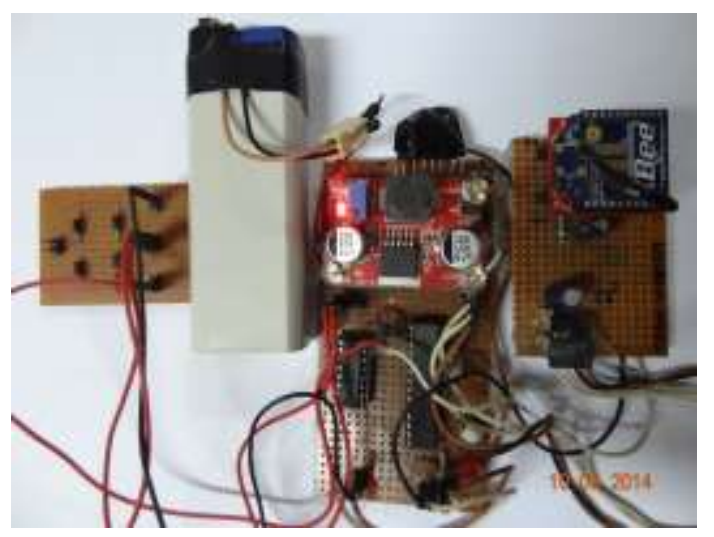

Fig. 8. Robots with magnetic wheels for carrying manipulator and ultrasonic probe [6]

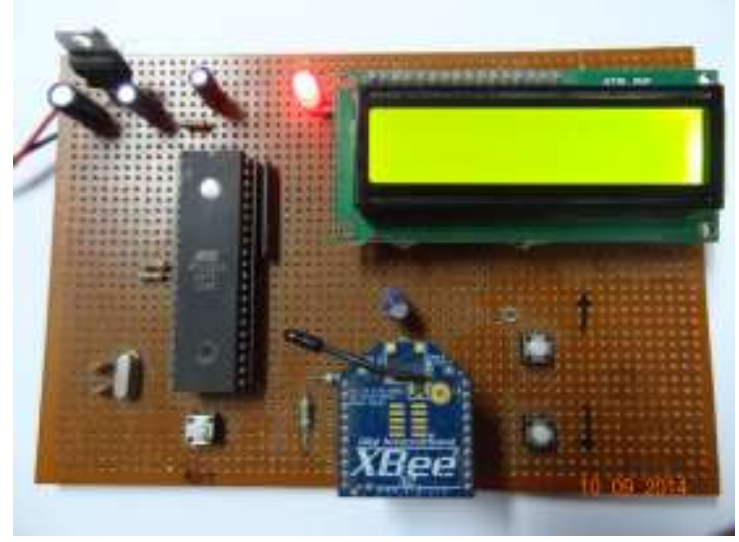

Fig. 9. Transmitter 


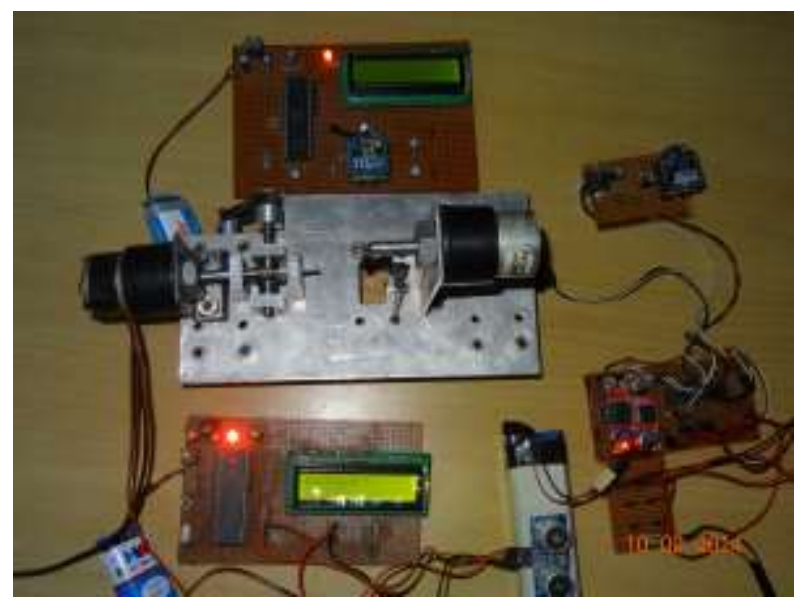

We have developed an influential hardware and software technology architecture that provide a communication among ultrasonic probe, robot, clearance gap module and operator. The following process done during inspection: 1) surface grinding 2) use couplant 3) probe setting 4) 3D simulation 4) scan path selection 5) data acquisition 6) data evaluation 7) control mechanism of robot 8) auxiliary device (storage) 9) reporting.

Fig. 10. Complete Manipulator

Data Acquisition

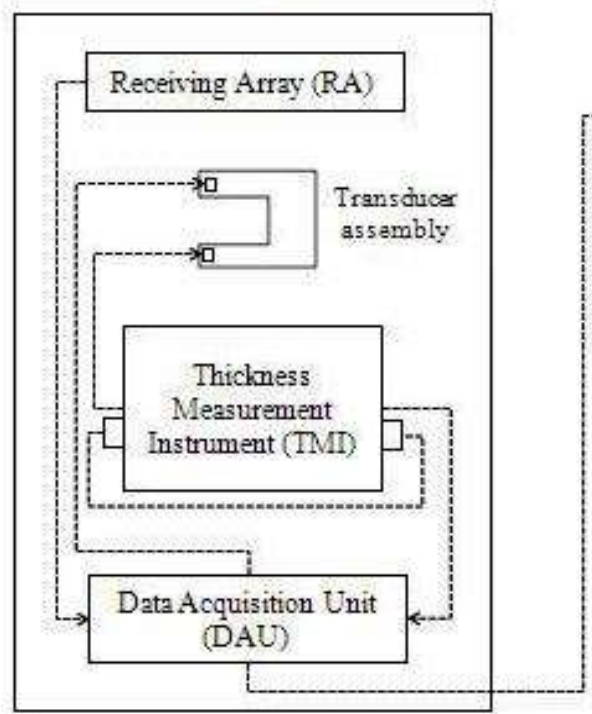

Fig. 11. Thickness and material composite measurement architecture

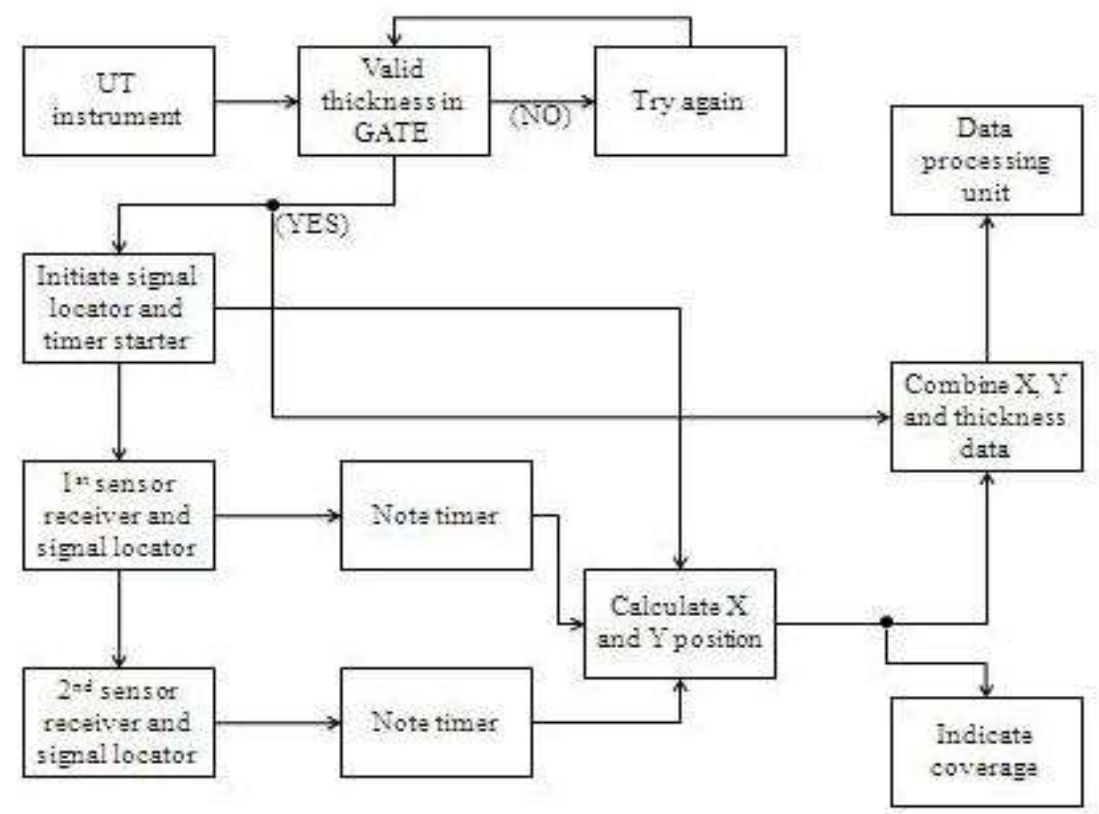

Fig. 12. Data Acquisition Subsystem [7]
Data Processing

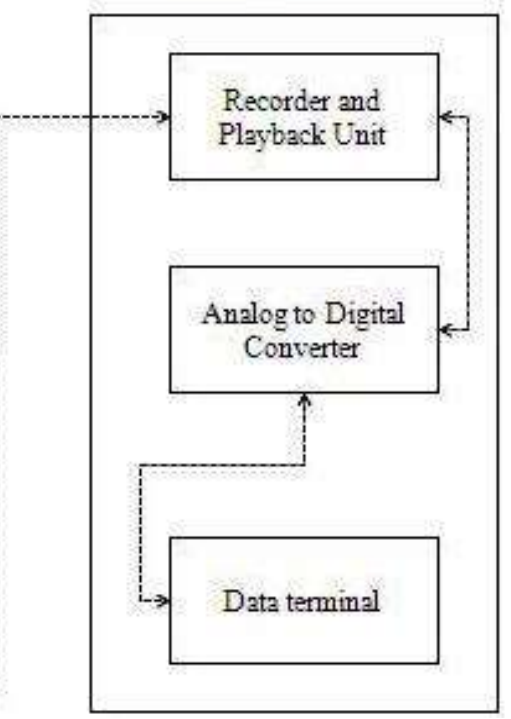




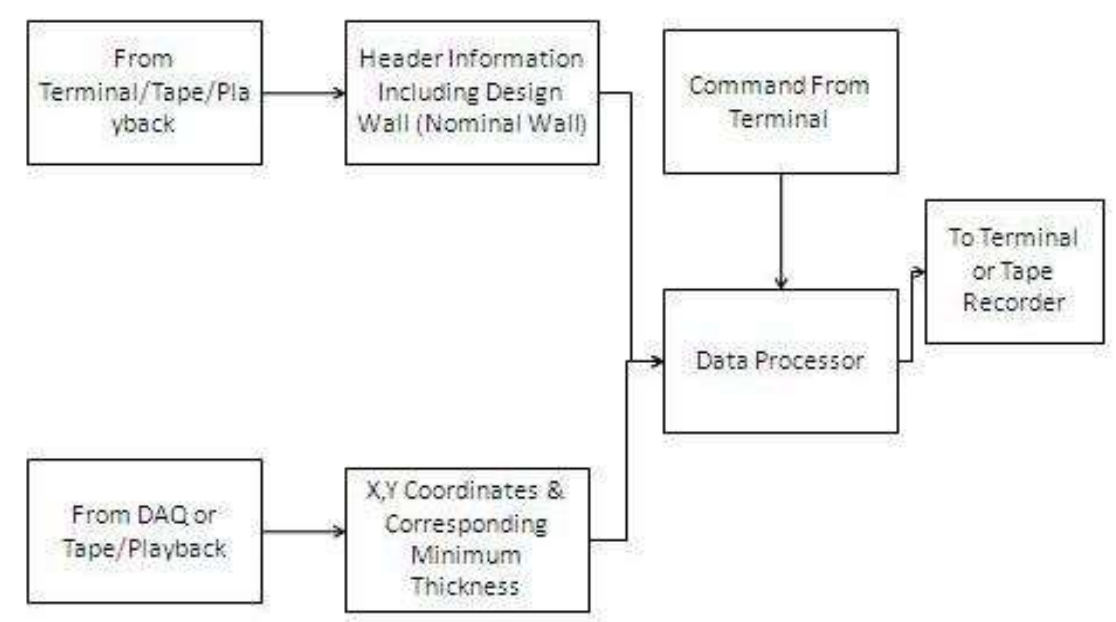

Fig. 13. Data processing

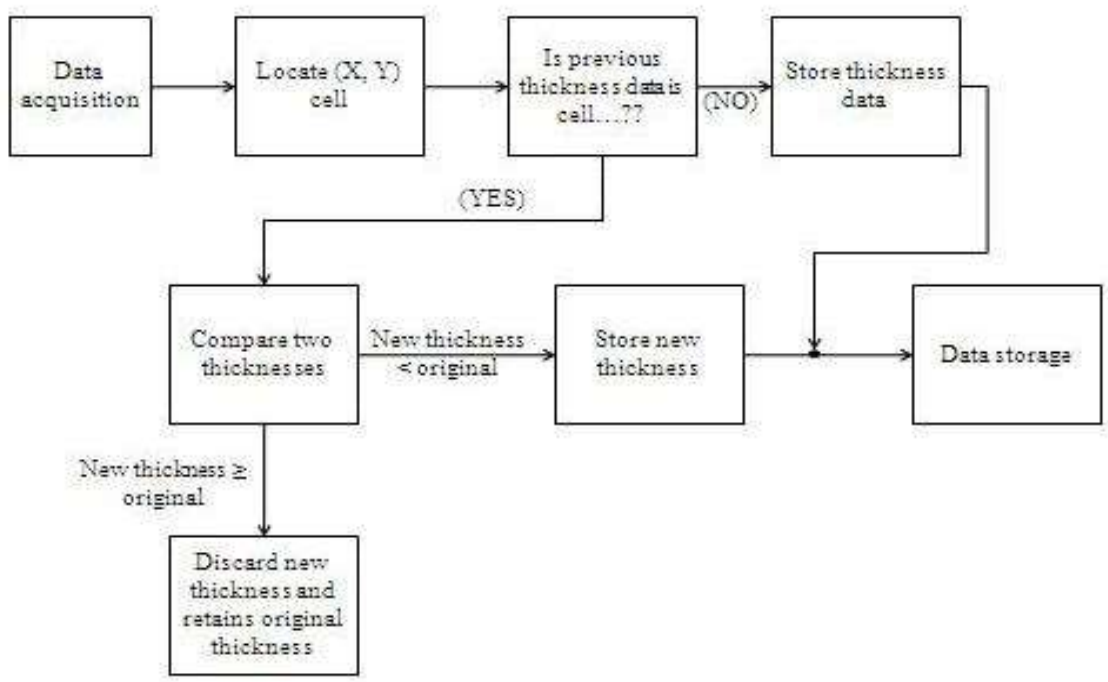

Fig. 14. Data storage [8]

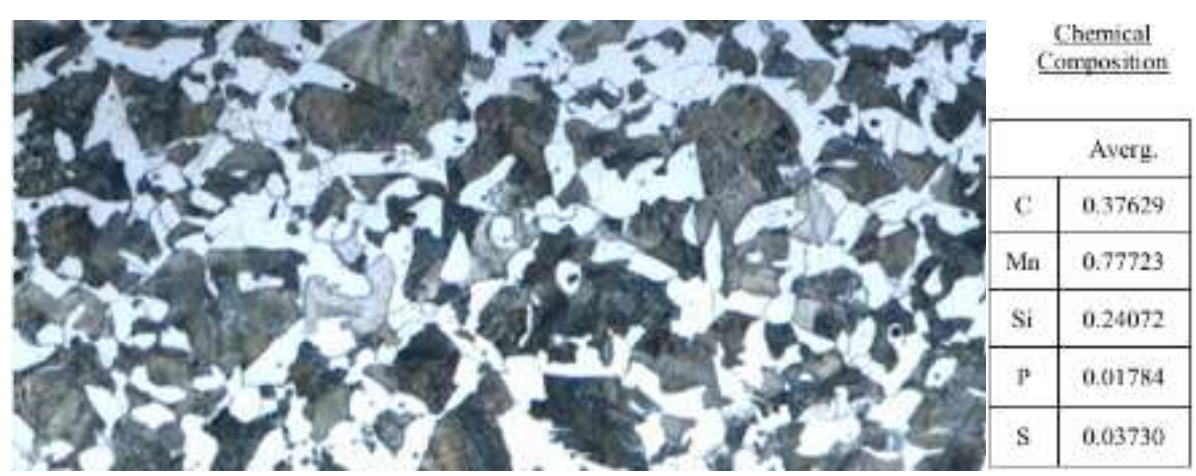

Fig. 15. Micro structural view at 200X magnification and Chemical Composition of Test Specimen

\section{RESULT AND DISCUSSION}

Calibration completed with respect to two aspects i.e. gain and time-base range. Before making calibration water or oil is used as a couplant for mismatching acoustic impedance of probe and test piece for accurate readings, in case of thickness measurement exercise. Ultrasonic in-service defect inspection is the most common technique used to detect immature cracks/leaks likely to be occurring in pipeline. The performance of an in-service ultrasonic flaw detection method based on or evaluated by the success of pulse waves received after scattered by microstructures. Therefore, the reliability of data directly depends on the signal noise ratio in case of small diameter pipelines. With the development of an automation with the help of microprocessor gave a birth to more and more new in-service ultrasonic inspection 
techniques with accuracy and reliability, and digital signal processing technologies also play a important role in this field. In sum, the trends of in-service ultrasonic inspection technologies for thin steel pipelines are described as follows: Although some signal processing techniques also have been presented to estimate pipe wall thickness, a real-time signal processing used in ultrasonic inspection called the Intelligent Signal Extraction System. For extracting a maximum accuracy the time-base range for the pipeline wall thickness is used, gain is adjusted according to first back wall pulse value, which is slightly below full screen height. The gain setting plays an important role in the scanning of subject throughout. But, the reflectivity at the corrode pipe is poor in comparison to the normal pipeline.

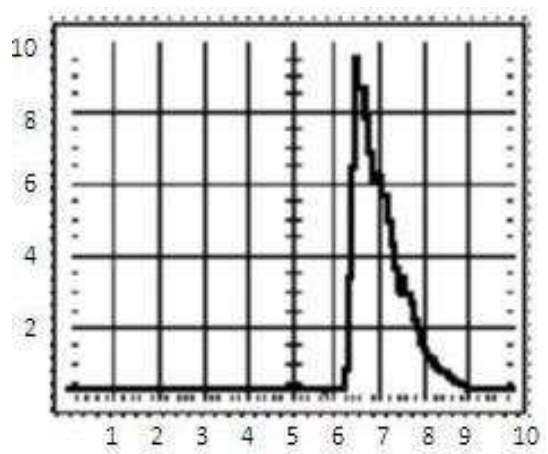

Fig. 16. Gain and time-base

Now the time-base are adjusted in this manner three pulse echo back wall of the pipeline are displayed in the set of $(3,6,9$.$) . The gain is adjusted in the manner last$ one "echo pulse" cover $80 \%$ of the total height.

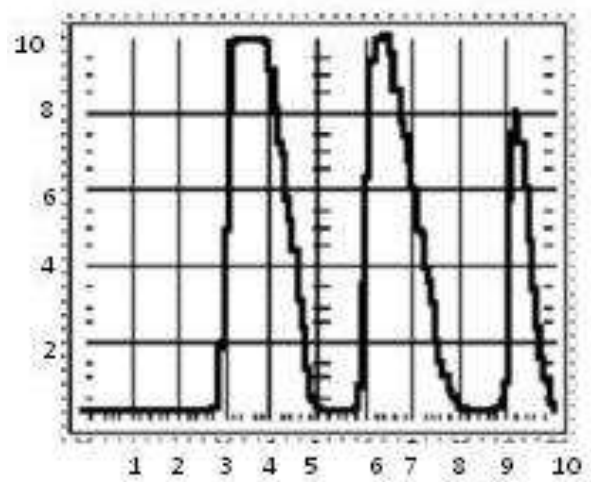

Fig. 17. Pulse echo set 3, 6, 9

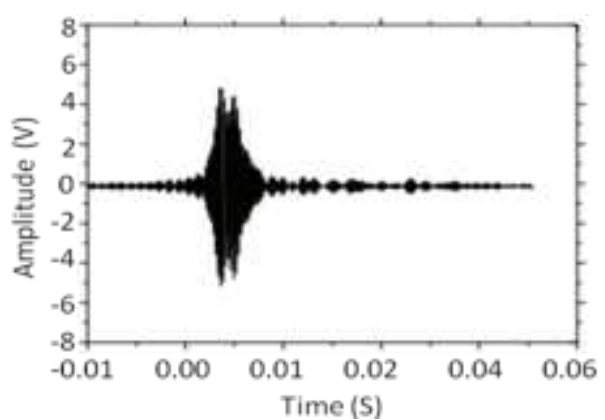

Fig. 18. UGC waveform before corrosion of sample 1

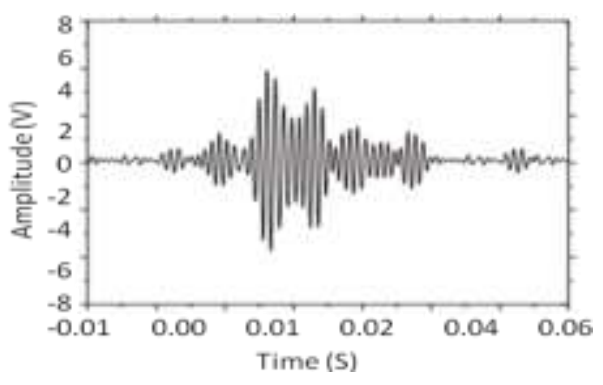

Fig. 19. UGC waveform after corrosion of sample 1 [9]

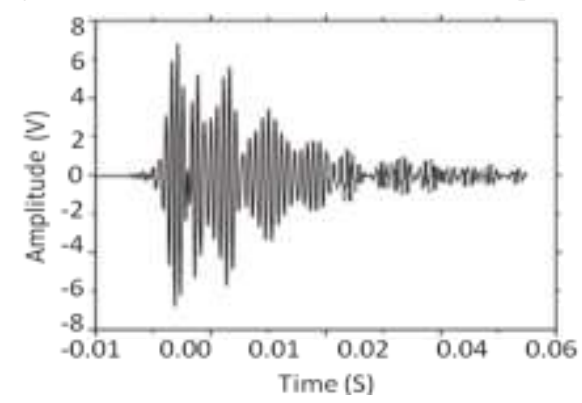

Fig. 20. UGC waveform before corrosion of sample 2

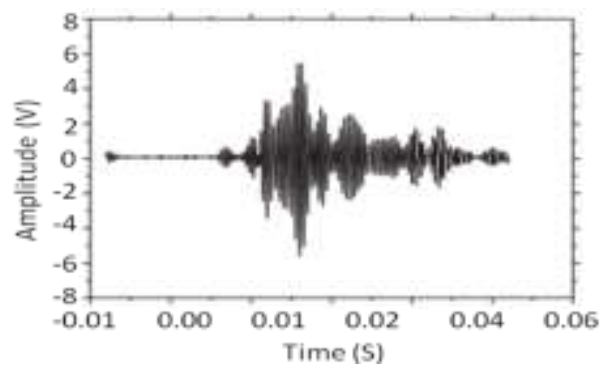

Fig. 21. UGC waveform after corrosion of sample 2

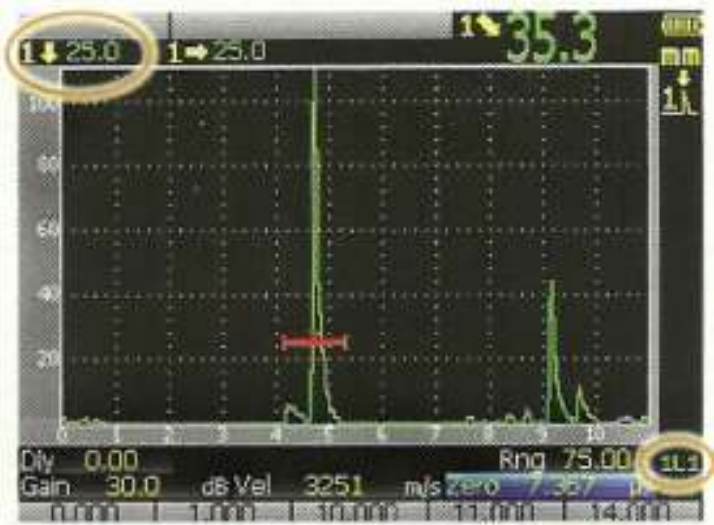

Fig. 22. A-Scan representation of rectangular pipe thickness

Table 1. Readings of rectangular pipe

\begin{tabular}{|c|c|}
\hline Database Grid (ID) & Thickness(mm) \\
\hline AA & 3.17 \\
\hline AB & 3.07 \\
\hline AC & 3.85 \\
\hline AD & 3.25 \\
\hline AE & 3.35 \\
\hline AF & 3.41 \\
\hline AG & 3.36 \\
\hline AH & 3.49 \\
\hline
\end{tabular}




\section{REFERENCES}

[1] Dr. Ravi B. Deo, Dr. James H. Starnes, Jr., Richard C. Holzwarth ,"Low-Cost Composite Materials and Structures for Aircraft Applications",

[2] Dr. Douglas S. Cairns, Lysle A. Wood ,"Composite Materials for Aerospace Structures", 2010 Distinguished Professor. Department of Mechanical and Industrial Engineering. Montana State University

[3] Dongsheng Li,1 Shuaifang Zhang,1 Wei Y ang, 2 and Wenyao Zhang, "Corrosion Monitoring and $\mathrm{E}$ valuation of Reinforced Concrete Structures Utilizing the Ultrasonic Guided Wave Technique", Hindawi Publishing Corporation International Journal of Distributed Senso, Volume 2014, Article ID 827130, 9 pages, http://dx.doi.org/10.1155/2014/827130.

[4] C. Sanchez, S. Hernández, D. Molpeceres, "Industrial Robotics at the services of the ultrasonic inspection of composite aeronautical components", JEC Singapore 2011

[5] Esmeralda CUEVAS, Miquel LÓPEZ, Mónica GARCÍA, "Ultrasonic Techniques and Industrial Robots: Natural Evolution of Inspection Systems", www.ndt.net/article/aero2012/papers/th2b1.pdf.

[6] Toshihiro Yukawa, Masayuki Suzuki, Yuichi Satoh, Hideharu Okano," Magnetic Part Design of Pipe-Surface Inspection Robot", 2006 IEEE.

[7] Lingyu Yu,Victor Giurgiutiu,Patrick POLLOCK," A Multi-Mode Sensing System for Corrosion Detection Using Piezoelectric Wafer Active Sensors ",Mechanical Engineering Department, University of South Carolina.

[8] T.R.Fortescue and R.Loffe1," DENSITY AND THICKNESS DETERMINATION BY X AND GAMM RAY ABSORBTION".

[9] M. García, F. J. Fernández, E. Cuevas ,"Design of ultrasonic inspection techniques for complex geometries in composites" 12nd NDT Spanish Congress.

[10] Hideo Nishino, simple method of generating for circumferential shear horizontal waves in a pipe and their mode identifications, Institute of science and technology, Japan 2006.

[11] W. Harara, Pit-Depth Measurement on Large Diameter Pipes by Tangential Radiography Using a Co-60 GammaRay Source, Russian Journal of Nondestructive Testing, Vol. 40, No. 11, 2004.

[12] Calkins, F.T., Smith, R.D., and Flatau, A.B., An Energybased Hysteresis Model for Magnetostructive Transducers, IEEE Transactions on Magnetics, submitted 10/97.

[13] Dapino, M.J., Calkins, F.T., and Flatau, A.B., On identification and analysis of fundamental issues in Terfenol-D transducer modeling, SPIE 1998, Proceedings on Smart Structures and Integrated Systems, paper \#23, Vol. 3329, $3 / 98$

[14] Glenn M. Light , Health Monitoring of Piping and Plate Using the Magnetostrictive Sensor (MsS) Guided-Wave Technology, Southwest Research Institute ${ }^{\circledR}$ San Antonio, TX 78228, 2010.

[15] K.Imano, possibilities of nondestructive evaluation of a pipe using air-coupled ultrasonic wave in the $\mathrm{MHz}$ range, IEICE 2008

[16] William L.MACMILLAN, Ezar J. AHREND, A new approach to boiler, pipeline and turbine inspections, 18th world conference on non destructive testing, 16-20 April 20-12, Durban, South Africa.

[17] M.Vossiek, V.Magori and H.Ermert, an ultrasonic multielement sensor system for position invariant object identification,IEEE Ultrasonic symposium.
[18] A.Vajpayee and D. Russell, automated condition assessment of boiler water wall tubes using remote field technology. A revolution over traditional and existing techniques, 10th international conference of the sloveninan society for non destructive testing, 2009.

\section{Authors' Profile}

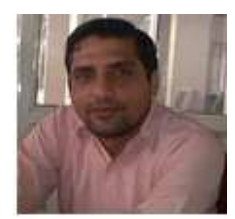

Vimal Upadhyay, He has done B.E from agra University, M-Tech in computer science from M.D.U Rohtak and presently pursuing $\mathrm{PhD}$ in IT from Indian Institute of Information Technology, Allahabad, India

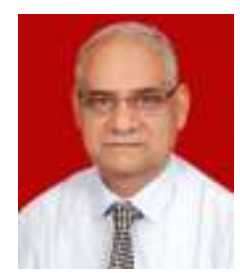

Prof G.N Pandey, Adjunct Professor, Indian Institute of Information Technology, Allahabad, India and Vice Chancellor Arunachal University of Studies,Arunachal Pradesh.

How to cite this paper: Vimal Upadhyay, G.N.Pandey,"Robot Based Preventive Maintenance System for In-Service Inspection of Equipments", International Journal of Intelligent Systems and Applications (IJISA), vol.7, no.4, pp.47-53, 2015. DOI: 10.5815/ijisa.2015.04.07 